\title{
EVERSION, ECOLOGY, TOUCH, AND RAIN: A POST-PC RHETORIC
}

\author{
David M. Rieder*
}

North Carolina State University

Raleigh, The United States of America

DOI: 10.7906/indecs.19.1.1

Regular article

Received: 21 February 2020.

Accepted: 21 February 2021.

\begin{abstract}
The post-PC era of computing offers digital rhetors an opportunity to innovate their inventional approaches. The new era is one in which an ecology of networked, distributed, sensor-based devices amplify our perceptions of self and world by changing the ecological relations that define our connections to our techno-social environments. By extending Casey Boyle's posthuman practice of rhetorical invention to the new computational era, rhetoricians can develop digital interactive projects that move participants by amplifying the choric bases of their perceptions of self and world.
\end{abstract}

\section{KEYWORDS}

rhetoric, digital, eversion, affect, post-PC

\section{CLASSIFICATION}

JEL: $\quad$ D83 


\section{EVERSION AND THE POST-PC ERA}

Since the era of the personal computer (PC) peaked over three decades ago, much innovative work related to popular computing has focused on smaller, less dramatic computers that are designed to support us peripherally, monitoring and responding to the relatively minor or mundane questions of the day. From Mark Weiser's contributions to early work under the auspices of ubiquitous computing, early natural-user interface (NUI) design at Microsoft, and more recent initiatives like pervasive computing and the Internet of Things (IoT) have contributed to a shift away from the desktop computer, which enculturated us to a dualistic relationship between the virtual and the real. During the reign of the PC, the virtual realm of the computer was behind the screen, or inside the computer; the 'real world' was outside of it, the two separate and distinct. And popular depictions of the virtual during that era were expressive of the dualistic split between the two realms. Films like the Wachowski's The Matrix reinforced this split (until the sequel), and William Gibson's cyberspace was a distal realm, separate and distinct from 'meatspace'. But even Gibson has recognized how far things have changed since the new era of popular computing has replaced the PC. In an Op-Ed in the New York Times, Gibson describes this distinction as follows [1]:

Cyberspace, not so long ago, was a specific elsewhere, once we visited periodically, peering into it from the familiar physical world. Now cyberspace has everted. Turned itself inside out. Colonized the physical.

The eversion about which Gibson wrote in 2010, which echoes scholarly work on hybrid space and mixed reality, is due largely to the change in the technical infrastructure, the "ecology of devices" in which we now live [2; p.15]. The small, smart, sensory-based, wireless, networked microcontrollers and -processes that are increasingly embedded in our everyday lives - in our homes and apartments, our cars, all kinds of built environments (airports, malls, office buildings, public bathrooms, subways, highways) to wearable technologies enbedded in sports equipment and clothing - contribute to what Gibson and scholar Steven E. Jones call our "everted lives." In his 2014 book, The Emergence of Digital Humanities, Jones offers a useful elaboration on the techno-cultural context to which eversion refers [3; p.19]:

The metaphor of eversion is particularly resonant, particularly useful, because it articulates a widely experienced shift in our collective understanding of the network during the last decade; inside out, from a world apart to a part of the world, from a transcendent virtual reality to mundane experience, from a mysterious invisible abstract world to a still mostly invisible (but real) data-grid that we move through everyday in the physical world.

Jones' depiction of the shift from a computational era characterized as an abstract, transcendent world apart (the PC era) to one that is combined with our everyday, physical world, especially in its more mundane moments, echoes Adam Greenfield's depictions of what he calls everywares. Greenfield describes an ever-growing number of micro-devices serving us from the interstices of our daily routines. These devices are meant to sense and respond to the activities that we perform on our way to the things that matter, like automating the process of paying tolls on the highway with RFID-based devices, or quietly standing in the corner, waiting and listening until we ask them to relay to us the weather or a news update. They are an essential part of today's data-grid, our contemporary techno-cultural infrastructure.

These devices may not be as attention-getting or dramatic as personal computers. In fact, they 
are oftentimes designed to be ignored, designed to be forgotten while they are supporting and maintaining the vectors and velocities of our quotidian lives; nonetheless, the make a profound contribution to our new perception of reality. When Gibson or Jones point to eversion, they are pointing to the recognition that some of what makes the virtual unreal during a PC era has mixed with the real in the era that has eclipsed it. This mixed, everted, post-PC techno-ecological world is the one in which rhetoric scholars and practitioners have an opportunity to innovate their approaches to invention and to what counts as a moving, rhetorical-engaging project. As I will argue shortly, Casey Boyle's call for a posthuman rhetorical practice is a compelling way in which to engage with the dynamics of the post-PC ecology of devices in which we find ourselves increasingly connected and immersed. Working from Gilbert Simondon's ontogenetic theory of becoming, Boyle develops an approach to rhetorical practice that leads to suasive movements of change in our perceptions of individual capacity by changing aspects of the affective capacity of the ecological milieu of which individuality is an expression. Change, in other words, does not originate in the all-too-Western belief in autonomous, rational self; rather, it begins in the ecological dynamic that in-forms individuality. When a digital rhetor designs an interactive media project, a rhetorically-engaging ecological experience, the user generates their own everting amplifications, thereby leading to changes in individual capacity.

\section{SENSORS AND ACTUATORS: AMPLIFICATION AND AFFECT}

Essential to the capacity of these devices to evert our lives are the sensors and actuators around which they are designed. Many of these devices rely on sensory data about the "real" or physical world, data which is then transduced through one or more actuators to then make a physical change in the world. For example, as daylight fades on a street, and the ambient light sensors in each of the street lamps are affected by that change, the lights-as-actuators affect the physical world when they turn on. This relationship between sensor and actuator in the device context is one of the key ways in which the blur between the virtual and the real is generated. These kinds of devices, which are invisible as infrastructure, change the way we perceive and feel our world, our capacities associated with our sense of self, and our expectations.

To better understand the role of sensors in the post-PC era is the following opening from Jennifer Gabry's book, How to Do Things with Sensors. Gabrys describes these devices in terms of their embeddedness in a network [4; p.1]:

The world of sensors is one of amplified connections. Sensors are meant to join up and speed up, while also facilitating and enabling. Whether these functions pertain to adjusting the lighting levels or advancing political engagement, a quickening of activity is expected to unfold through sensors.

To make changes to the ecology in which we are associated, sensory data is key. Sensory data is the initial connection with the physical world, which a computational system creatively transduces, subsequently sending it back through one or more actuators to the physical,. The process, from sensor to actuator, is how eversion is supported. Like a stitch in time, these devices introduce a different valence or capacity into the everyday structure of our lives.

To build on the argument, regarding the need for innovation, sensors and actuators relates to Gilles Deleuze's Spinoza-inspired definition of a body. In his essay, "Spinoza and Us," Deleuze explains that, for Spinoza, the definition of a body is based on two propositions. The first is kinetic: "a body, however small it may be, is composed of an infinite number of particles; it is 
the relations of motion and rest, of speeds and slowness between particles, that define a body" [5; p.123]. The second is concerned with its affective capacities: "a body affects other bodies, or is affected by other bodies; it is this capacity for affecting and being affected that also defines a body in its individuality" [5; p.123]. Spinoza's definition is like a two-dimensional visualization, the lines expressive of its kinetic and dynamic dimensions, waxing and waning with each passing moment. Importantly, the definition can be mapped on to most any object or event: an insect or animal, a poem, a melody, a gesture. In fact, Deleuze offers the following description of a body in his book on Nietzsche: "Every relationship of forces constitutes a body - whether it is chemical, biological, social or political. Any two forces, being unequal, constitute a body as soon as they enter into a relationship" [5; p.37]. Returning to the street lamp - and focusing on the second axis, the photosensitive chemical in the sensor, cadmium sulfide (CdS), becomes a body under Deleuze's definition in relation to the sun's rays. During the day, when the number of photons hitting the semi-conductive powder are high, $\mathrm{CdS}$ allows electricity to flow freely across it. But when the sun goes down, and the number of photons affecting the powder are fewer, CdS acts as a resistor. A device designed to monitor the affective state of that CdS-photon body can transduce its affective state toward switching on or off the electricity from the city's grid to the bulb that lights the street, which, too, can be defined as another kind of body. And from a broader point of view - and one that returns us to the level of a user's experience of everywares - the feeling of well-being or safety that a pedestrian might experience when the street lamps begin illuminating the darkness of the street, can be viewed as another set of affective capacities, another 'relationship of forces' or body is amplified.

The point of making the connection to Deleuze's Spinozist body is that the devices that change the ecological arrangement with which we are connected are meant to be a part of the world, to affect aspects of our mundane, everyday routine, operating from the interstices. Those devices, due to the ways in which they augment or amplify aspects of our everyday life, demand a different approach to both valuing and working with them. When these post-PC technologies quietly monitor and respond to aspects of our life, they change the ecology that is the basis for our felt and perceived world, and that ecological change requires a different approach to invention, one that focuses on an alternative logic of engagement, a distinct way of thinking through things, a "bastard reasoning".

\section{CONNECTING WITH THE CHŌRA}

The ancient notion of the chōra has found its way back into rhetoric theory as a way of engaging with the alternative logic of our emotions, feelings, and affect in a techno-ecological context, which is a context introduced, in large part, by the kinds of devices mentioned above. Thomas Rickert's essay, "Toward the Chöra," is an important contribution to these ends. In his essay, Rickert offers a close reading of the chora outside of its limited place in Aristotle's philosophical system by focusing on the uses/difinitions offered by Plato and much later Julia Kristeva, Jacques Derrida, and the American scholar Gregory Ulmer.

In regards to the latter scholars uses of it, Rickert writes the following [6; p.252]:

[T] he chöra transforms our senses of beginning, creation, and invention by placing them concretely within material environments, informational spaces, and affective (or bodily) registers. Thus, [Kristeva, Derrida, and Ulmer] are interested in how the chōra as an ancient line of thinking can iluminate contemporary concerns. 
For Rickert, the material environments and information spaces in which we find ourselves today challenge rhetoricians to develop new methods of inquiry - specifically inventional methods that do not rely on the classical, Aristotelian topoi or on modern incarnations of it, like Kenneth Burke's pentad. These approaches work well within language-based systems designed for "discursive, print-based notions of representation and rationality" [6; p.252], Rickert reminds us. But in a post-PC era, these "bookish" approaches are not resilient enough to match the new dynamics of distributed and networked spaces that the ecology of devices has introduced. It turns out that a shift away from the Aristotelian legacy of the topoi for the older notion of the chora resonates more productively with the dynamic and generative experience of space found within an era of eversion. In what follows, I will focus on Plato and Kristeva.

In Rickert's reading and summary of recent scholarship about the Platonic dialogue, Timaeus, in which the chora is discussed at length, the term relates to a theory of creation that begins not from a fixed, stable starting point but rather a "distribution (or matrix) of beginnings" [6; p.257]. The Platonic chora is more like a receptacle or matrix comprising a complex distribution of forces. It the source of all becomings, but it does not resemble that which emerges from it. It is elusive, hidden from direct view. It is the source of creation, but it exceeds the scope of the human intellect. It would seem to have a lot in common with the way affect is described by Melissa Gregg and Gregory J. Seigworth in their introduction to their collection, The Affect Theory Reader [7; p.1]:

Affect, at its most anthropomorphic, is the name we give to those forces visceral forces beneath, alongside, or generally other than conscious knowing, vital forces insisting beyond emotion - that can serve to drive us toward movement, toward thought and extension, that can likewise suspend us (as if in neutral) across a barely registering accretion of force-relations, or that can even leave us overwhelmed by the world's apparent intractability.

It is for this reason that the chora requires a different approach to reasoning, since it is expressive of a different logic, a "bastard reasoning," as it is described in Plato's dialogue [6; p.259, 8; 51a-51b, 8; 52b].

For Kristeva, in works like Revolution in Poetic Language, the chora is used in association with what she calls the semiotic realm. Kristeva posits two realms, the symbolic and semiotic. The symbolic realm is the realm of language and meaning. The semiotic is the realm of the "emotions, sensations, and other marks and traces of psychical and material experience" [6; pp.260-261]. In an article that includes both a summary of an application of Kristeva's theory of the chora, Brian L. Ott and Diane Marie Keeling offer the following explanation [9; p.366]:

Adapting Plato's conception, Kristeva understands the chora as the undifferentiated state between mother and infant prior to the acquisition of lanauge and the paternal law. It is a womb-like enclosure - a sonorous envelope in which the prenatal and newborn infant feels at one with the sounds and sensations of the mother. .For Kristeva, the chora corresponds to and enables the semiotic (or nonreferential) dimensions of rhetoric.

For Kristeva, as an infant acquires language, the vital and original significance of the semiotic is largely forgotten, the role of the symbolic largely eclipsing it. But the semiotic cannot be completely ignored. Without the chora, the humanities and sciences are little more than "archivistic, archaeological, and necrophiliac" [6; p.261, 10; p.13]. The chora is a necessary and 
vital "extra-linguistic" dimension of human life, including artistic and intellectual creativity. As Kristeva argues in Revollution in Poetic Language, it is an essential source of avant-garde literature, poetry, and other experimental realms.

Traditional approaches to communication and invention rely on a stable, autonomous self who exists separate and distinct from the world, and whose individuality is predicated on a rational mind that communicates through language. It is a traditional subject propped up by a host of dualisms that work in parallel, and which include mind/body, inside/outside, truth/appearance, and more. Like conceptual scaffolding, these dualisms uphold a subject who is meant to be autonomous, individual, and rational. But as the dualisms that prop up this subject become blurred in a techno-cultural era based on an ecology of devices that contribute to eversion, an alternative conceptualization of self is required. Rickert writes, "In the new spatial paradigm, minds are both embodied, and hence grounded in emotion and sensation, and dispersed into the environment itself, and hence no longer autonomous" [6; p.251].

A focus on the chora is a step toward appreciating the complex, generative dimensions and capacities of the distributed set of forces comprising the ecology of devices that are everting the spaces in which we live and work.

The next step is to work toward a sense of practice. How, in other words, can digital rhetoricians innovate traditional practices based in the symbolic realm in order to work alongside the capacities of the choric ecology of post-PC devices everting our lives? For a possible answer to that question, I turn to Casey Boyle's Rhetoric and Posthuman Practice.

\section{A POSTHUMAN APPROACH TO POST-PC RHETORICS}

In his approach to rhetorical practice, Boyle relies on the same definition of the Deleuzian-Spinozist body, linking it to his approach. For example, Boyle writes, "this project finds the body, any body, to be a set of tendencies that affects others and is affected by others. In this way, a body cannot be neatly defined except as a relational process, one that emerges with and through practices" $[11 ;$ p.5]. In this definition, Boyle references implicitly the second dynamic proposition from Spinoza's definition. For Boyle, a posthuman approach to rhetorical practice is derived in part from relational (read: networked and distributed) forces comprising human and non-human "actors." It's an approach that adopts in order to better respond to the changing dynamics of the post-PC era, which is an era in which a perceived change has occurred between self and world, which is epitomized by the experience of eversion. In fact, echoing some of the same techno-cultural context that Rickert described at the beginning of his article, Boyle writes, "Increasingly compounded by digital forms of mediation, our fast-evolving information moment interrupts long-standing divisions between human subjects and nonhuman objects" [11; p.6] (my emphasis). With this interruption in mind, Boyle offers an approach to rhetorical practice and invention that is meant to work from within this moment of perceived eversion.

Boyle's approach to practice is strongly influenced by Gilbert Simondon's work. He draws on a wide range of Simondon's theories. For the purposes of this essay, I will focus on the following three ideas: Simondon's ontogenetic approach to individualization, his theory transduction (and information), and his description of the ways in which individuality emerges and continues to transform toward new individualizations from a choric-like process of in-formation born of a metastable milieu.

Regarding his ontogenetic approach, Boyle explains that Simondon downplays the historical 
interest in ontology in favor of ontogenetics. The difference is that the latter foregrounds the ongoing process of change and becoming, past, present, and future, that defines an individual's current state. For Simondon, an ontological approach to individuality tends to "elevate a principle of individuation over a process of individuation" [12; p.76]. This is a problem because the former does not adequately account for the ways in which individuality comes to be, and how that being is continually in-formed by “'other influences' that Simondon claims could be "equally important to the emergence of that individuated being" [12; p.76]. An ontological approach begins with a finished product (of individualization) and reverse engineers a description of the origins its form from the principles and properties comprising that final version. Harkening back to the role of the chora, we could say that the ontological approach does not adequately account for the genotextual matrix of influences, the semiotic background from which any expression of individuality emerges. Instead, we begin from the symbolic, and extend its paternal logic as far back as necessary, ignoring the material matrix from which what exists was and is continually in-formed. The "bastard logic" of the semiotic is ignored.

Related to Simondon's focus on ontogenetics is his theory of information. Boyle explains that for Simondon, information is a complex process of becoming or individuating [11; p.22]. An important first step toward understand this claim is to appreciate the difference between two approaches to what information is and does. The first values information for what it transmits. Information associated transmission reduces it to "that which can be transmitted as meaningful content between individual points" [12; p.74]. The second associates information with an ongoing and dynamic process of transduction. In their book, Physical Computing: Sensing and Controlling the Physical World with Computers, Dan O'Sullivan and Tom Igoe define the process of transduction in relatively simple terms. It is "the conversion of one form of energy into another" [13; pp.xix-xx]. Related to this is Simondon's more complex description of transduction, which Boyle describes as "a signal that changes as it travels across media, transversals that might include biological, cultural, and technological registers" [11; p.22]. He offers the example of sound as it is is transduced from air vibrations through the diaphragm of a microphone, transduced again into an electrical impulse, earbuds, back through air vibrations and then through the human ear drum [11; p.22]. Returning to the earlier example of the street light, the sequence of transductions include the change of photons of light from the sun to chemical reaction in the cadmium sulfide that leads to changes in the analog sin wave of electricity coursing through that part of the circuit, which is then transduced into a numerical/digital value that can then be used by software to subsequently amplify or attenuate the analog sin wave associated with the light level of the street light in another part of the overall circuit. And related to the way transductions can affect biological, cultural, and technological registers, in addition to the abovementioned technological registers of the process, there are transductive mechanisms associated with the human eye (biological) and the sense well-being and safety that associated with a well-lit street at night (cultural).

With this idea of transduction in mind, information is a never-ending process in and through which individuation occurs. "Information," Simon Mills explains, "is the term used to describe the individuation process from a number of different perspectives" [12; p.44]. Relatable once again to the chora, we can think of information as a verb. Individuality is an ongoing process of in-formations, one after the next, born out of a metastable matrix of possibility. Like the mother-water in which Simondon's favorite crystal grows, individuality grows from within the metastable ecology of material-maternal forces. Information, in this description, is an amplifying structure in and through which transductions occur. Individuality is, after all, a complex set of 
relations. And based on this unending transductive process of in-formed, serial becomings, Boyle argues that rhetorical persuasion is "an exercise in amplifying and attenuating affective forces in an ongoing attempt to individuate bodies." [11; p.88]. In contrast to the classical approach to invention, which endeavors to find the available means of persuasion, Boyles posthuman approach "repeatedly poses the rhetorical question of "what a body can do'?" [11; p.59]. This question, which is one that resonates with the Deleuzian-Spinozist definition of a body, looks for ways in which to strengthen or weaken some of the affective capacities associated with an individual's metastable ecology; so, echoing Boyles' definition of persuasion, rhetoric is now concerned with discovering the available means of changing the affective dimensions of a body in order to change the perceived and/or felt characteristics of a given body.

This approach resonates with the following quote from Erin Manning's monograph, Always More Than One, from which Boyle quotes. Manning writes, "A body is a complex activated through phases in collision and collusion, phasings in and out of processes of individuation that are transformed - transduced - to create new iterations not of what a body is but what a body can do" $[11 ;$ p.78, 14; p.19]. So, my argument is that rhetorical practice is the discovery of the available means of intervention among some of these processes of individuation. When we amplify or attenuate some of the affective relations comprising a given phase of individuality, we introduce openings for new iterations to emerge.

In a post-PC era in which our sense(s) of self - our perceptions of the world; our feelings as expressions of affective capacity in the world; our sense-abilities - are inextricably linked to a choric-like ecology of devices, changes to that ecology are where a digital rhetor can practice this new approach to persuasion. In answer to the question about innovative methodologies/practices, for digital rhetors working in and with the sensors, actuators, and micro-processes comprising the new post-PC era, we develop interactive environments that, in practice, amplify or attenuate some of the relations comprising our sense-abilities of self.

\section{AMPLIFICATIONS OF DELIGHT: RAIN ROOM}

Earlier, I described the way in which many of the devices comprising the new post-PC era tend to work at the periphery of our attention, quietly moving or suading us toward new senseabilities of individuality, new perceptions of our world. But for a digital rhetorician developing interactive projects, these same technologies can be used in dramatic, overt ways. A "dramatic" project that both epitomizes some of the sensory capabilities of the new era and demonstrates how (posthuman) rhetorical practices can contribute to a perceived and felt change in self, which would signal a moving/suasive experience, the digital interactive installation, Rain Room, is a compelling example [15].

Rain Room was developed by two of the founding members of the London-based collective Random International, Hannes Koch and Florian Ortkrass. The initial installation of Rain Room was in the Barbican Gallery in London (2012-2013). Its popularity led to installations at the Museum of Modern Art (MOMA) in New York City (2013), the Los Angeles County Museum of Art (LACMA) in Los Angeles (2015-2017), the Sharjah outside of Dubai (2018-), the Yuz Museum in Shanghai (2015-), and the Australian Centre for the Moving Image (ACMI) in Melbourne (2020); it is a part of the permanent collections at the LACMA and the Sharjah. Rain Room has been described as the experience of being in a rain storm without getting wet. When it opened in 2012 at the Barbican in London, The Guardian's Architecture and Design critic, Oliver Wainwright, said the following on camera [16]: 
Not only is it raining indoors, but I'm not even getting the slightest bit wet wherever I go. It's almost like I'm giving off some kind of wind that's pushing the rain away. [It] somehow responds to me like I have a magnetic field. Wherever I go, it opens up around me.

Related to the surprise and excitement that Wainwright expresses during his walkthrough of the installation, are descriptions like the following in the Australian Design Review [17]:

Expressions of delight, surprise, disbelief - and often, children especially, rushing through the droplets with complete abandon-offer insights into visitors' personalities. The un-ticketed, temporary experience gives an immediate response and is also democratic; anyone can play God for 10 minutes, if only they're prepared to queue!

Related to eversion, the experience introduced by projects like Rain Room infuse some of the 'unreal' characteristics of the virtual with the real, contributing to changes in affect that are relayed at the symbolic level with words like delight, disbelief, and a sense of something freedom associated with the gods.

Technical specifications about the exact materials and design of Rain Room are difficult to find, but a general list includes the following: 2500 liters of recycled water, a water-management system, injection-molded ceiling tiles, a grated floor (for water collection), steel beams, hundreds of computer-actuated solenoid valves (water nozzles or valves for the simulation of rain), custom software, and 3D, depth-tracking cameras. These materials are part of the choric infrastructure of the space.

Based on that list of materials, we can speculate that they would contribute to the moving or suasive experience as follows: the depth cameras around the installation space are used to detect and track the movement of people within the space; the custom software would be used to remap the 3D data related to people in the space with 2D grid of water valves in the ceiling above them, turning them off or on; and the grated floor would enable the rain fall to be collected, returned to, and recycled through the water-management system. The effect of all of these materials and processes is the experience of walking through a rain storm without getting wet. The water valves above one or more people in the installation space are turned off in "real time," so that a roughly six-foot radius around each user remains dry.

Rain Room is a compelling example of how the paradigm of physical computing can be used methodologically as a choric-like structure that in-forms its users toward new atunements - new feelings, new perceptions, new relations - with the world. As participants interact with the installation, they engage in and experience (read: feel) changes in the capacities of their bodies, and those changes can contribute to a change in perception that persists after they leave the installation. The project is a compelling example of the ways in which digital rhetors can design a suasive environment that leads to changes in the affective capacities of bodies, thereby contributing to an ontogenetic change or becoming. In fact, thinking a bit more granularly about the ways in which Rain Room as a choric space leads to ontogenetic changes, I will describe an experience of being caught in an unexpected rain storm. The feeling of unwanted rain drops touching my skin as well as the feeling of clothes that have become heavy, cold, and stuck to my body is baseline from which to appreciate what Rain Room accomplishes.

My memories of being caught unexpectedly in a rain storm are filled with mostly negative feelings and emotions, such as frustration or dread or panic. As the rain hits me, I have the sense 
that I cannot escape it. Related to this feeling, the grandeur of the space in which I've been walking gives way to something far denser and more opaque. The taps of rain drops on my skin, the feeling of cold water streaming down my back, and the heavy feeling of my clothes, all contribute to a change in affect as I look for a shelter or the quickest way home. Before the rain, unless it's windy or the sun is very hot, I'm not usually as aware of my body as I walk around. But when it is raining, my body becomes conspicuous; I cannot escape it, either, and that idea contributes to feelings of frustration. It also contributes to an attenuation in my thinking; I'm less able to think broadly or deeply on a subject while caught unawares by a rain storm. Curiously, as the rain hits my body, I can intuit the size of the rain drops (and the 'heaviness' of the rain) by how hard they hit me and the ground; moreover, I can, at first, sense how cold the rain is. If its gusty, I can intuit the direction of the wind, too, based on the angle at which the drops hit my face, neck, and arms.

Virtually all of the sensations, feelings, and emotions associated with the (negative or stressful) experience of being caught unexpectedly in the rain relate to the human sense of touch. Touch, Matthew Fulkerson has argued, "involves a wider range of sensory transducers and informational channels than the other senses and has a complex structure closely aligned to both bodily awareness and exploratory action" (1). Touch is far more than skin deep, which is why Fulkerson states that the "shortcomings in our most basic understanding of the senses and sensory awareness" (3). In his book, The First Sense, Fulkerson explains that touch can involve noncutaneous forms of awareness, such as proprioceptive awareness as well as the awareness of movement (kinetic). It can include the feelings of aches and pains, tingles, itches, twitches, and various types of muscle tightness. And as far as concerns cutaneous touch, it can include sensations of objects and surfaces that are hot, cold, soft, hard, smooth, and rough. Touch can also be experienced distally, which means that we can experience objects with which we are not in direct contact. We can feel the roughness or smoothness of the paper on which we are writing from the pencil we are holding. And we can track the direction and progress of a pet, like a cat, as it makes its way from one end of our bed toward our pillow in the morning. It is not touching us directly, but we can "feel each step and track the cat as it navigates around obstacles and marches on toward our face" [18; p.145]. The pencil and the bed in these examples are media through which distal information is translated or transduced to our "sensory surfaces" [18; p.146].

In Rain Room, the experience of being caught in a rain storm - the anxious and negative feelings; the inescapability of our body; the frustratingly unstoppable feeling of rain drops hitting you; the coldness leaching under our skin; our sopping wet clothings dragging us down physically and emotionally - are attenuated. All of the anticipation of discomfort and agitation are gone, and in the place of those feelings and emotions are far more uplifting ones, like surprise and wonder and delight. The two-dimensional ceiling of water valves in the installation space turn off above us, creating a rain-free, three-dimensional space around us, like a spot light following us in the dark. Our expectations and the practices of life for which they relate are not matched, and the attenuation of the expected experience leads to a concomitant rush of joy and a sense of delight as we experience something unexpectedly positive, due to eversive technologies comprising the installation, which change the conventional ecological dynamic on which our bodies expect such an experience to occur.

The ways in which Rain Room everts the conventional experience of rain, thereby changing our expectations, can be further explained by late- $19^{\text {th }}$ century theory of the physiological origins of our emotions, which is oft-cited in affect studies. The theory is known as the James-Lange theory 
because William James and Carl Lange independently published similar arguments within a year of each other. Both argued that our feelings and emotions originate in physiological changes in our bodies. Conventional wisdom has us believe that our feelings and emotions originate in a mental perception, but James and Lange argued that the emotions, i.e., the words that we have mapped onto specific ranges of affective changes in our bodies come after. A saying attributed to William James' explanation of the theory, which is found in his 1884 essay, "What is an Emotion?", is the following: we do not run away from the bear because we are scared; rather, we are scared because we are running away from the bear. The saying is derived from the following lines in James' essay:

Common sense says, we lose our fortune, are sorry and weep; we meet a bear, are frightened and run; we are insulted by a rival, are angry and strike. The hypothesis here to be defended says that this order of sequence is incorrect, that the one mental state is not immediately induced by the other, that the bodily manifestations must first be interposed between, and that the more rational statement is that we feel sorry because we cry, angry because we strike, afraid because we tremble, and not that we cry, strike, or tremble, because we are sorry, angry, or fearful, as the case may be. [19; p.190] (my emphasis)

The point of the James-Lange theory is that the feelings of surprise, joy, and delight in Rain Room are expressive of the realization among participants that their expected emotional state is not matched by the anticipated 'bodily manifestations' of being wet and miserable. That is what makes projects like these (and the post-PC technologies on which they are based) so compelling for digital rhetoric. What these everting technologies offer digital rhetors is the opportunity to change the affective capacity of an interactive space, to change its choric capacities. The change in our affective state or capacity occurs before our perception of the event and our emotions about it. Rain is a compelling example of what a posthuman, rhetorical practice can be in a postPC era of everting, sensory-based technologies.

\section{CONCLUSION}

As in most humanistic fields in the $21^{\text {st }}$ century, changes in technology, especially those related to the new era of post-PC everywares, challenge digital rhetoricians to shift their inventional practices. Combining the scholarly approaches to concepts such as chora, eversion, and ontogenesis, allows us to view new and innovative possibilities for rhetorical practice. For example, rather than beginning (and ending) with an autonomous subject - one who is moved primarily by and through language, the origins for change now occur in the choric, metastable ecology of devices. From within this ecological milieu, digital rhetoricians design interactive environments that have embedded within their interactive logic a way for participants to selfamplify some of the relational capacities that in-form their sense of self. In other words, by interacting with a digital interactive project, like Rain Room, participants engage in their own suasion, their own becoming. Boyle's posthuman practice is a compelling approach to the ecology of devices in which we are now imbricated.

\section{REFERENCES}

[1] Gibson, W.: Google's Earth.

The New York Times, 1 September 2010: A23,

[2] Greenfield, A.: Everyware: The Dawning Age of Ubiquitous Computing.

New Riders Publishing, San Francisco, 2006, 
[3] Jones, S.E. The Emergence of Digital Humanities.

Routledge, New York, 2014,

[4] Gabrys, J.: How to Do Things with Sensors.

University of Minnesota Press, Minneapolis, 2019,

[5] Deleuze, G.: Nietzsche and Philosophy.

Translated by: Tomlinson, H. Continuum, New York, 1986,

[6] Rickert, T.: Toward the Chōra: Kristeva, Derrida, and Ulmer on Emplaced Invention.

Philosophy \& Rhetoric 40(3), 251-273, 2007,

http://dx.doi.org/10.1353/par.2007.0030,

[7] Gregg, M. and Seigworth, G.J., eds.: The Affect Studies Reader.

Duke University Press, Durham, 2010,

[8] Plato: Timaeus.

Translated by: Bury. R.G. Harvard University Press, Cambridge, 1929,

[9] Ott, B.L. and Keeling, D.M.: Cinema and Choric Connection: Lost in Translation as Sensual Experience.

Quarterly Journal of Speech 97(4), 363-386,

[10] Kristeva, J.: Revolution in Poetic Thought.

Translated by: Waller, M. Columbia University Press, New York, 1984,

[11] Boyle, C.: Rhetoric as Posthuman Practice.

The Ohio State University, Columbus, 2018,

[12] Mills, S. and Simondon, G.: Information, Technology, and Media.

Rowman \& Littlefield International, Ltd, London, 2016,

[13] O’Sullivan, D. and Igoe, T.: Physical Computing: Sensing and Controlling the Physical World with Computers.

Cengage Learning, New York, 2004,

[14] Manning, E.: Always More Than One: Individuation's Dance.

Duke University Press, Durham, 2013,

[15] Random International: Rain Room. accessed $20^{\text {th }}$ February 2020,

[16] The Guardian: Barbican's Rain Room: it's raining, but you won't get wet. https://www.youtube.com/watch?v=EkvazIZx-F0, accessed 20th February 2020,

[17] In Review: Rain Room.

Australian Design Review. June 21, 2013, accessed $20^{\text {th }}$ February 2020,

[18] Fulkerson, M.: The First Sense: A Philosophical Study of Human Touch.

The MIT Press, Cambridge, 2014,

[19] James, W.: What Is an Emotion?

Mind 9(34), 188-205, 1884. 